\title{
Importance and Feasibility of Animal Welfare Measures from a Consumer Perspective in Germany
}

\author{
Carolin Winkel $^{1} \cdot$ Sirkka Schukat $^{1} \cdot$ Heinke Heise $^{1}$ \\ Accepted: 25 August 2020 / Published online: 21 September 2020 \\ (C) The Author(s) 2020
}

\begin{abstract}
The subject animal welfare is increasingly in the public discourse. Consumers and policymakers are increasingly demanding products that are produced under increased animal welfare standards. The profession of the farmer involuntarily gets into disrepute. Many consumers want fundamental changes in pig farming, but are not aware of the consequences of implementation. In this representative study, consumers $(n=1101)$ were asked about their assessment of 33 animal welfare measures with regard to their importance and the feasibility of implementing those measures. With the help of a four-field matrix, both the perceived importance and the feasibility of the animal welfare measures surveyed were brought together. The results show four possibilities: important and easy to implement, important and not feasible, not important and easy to implement as well as not important and not feasible. The results show that any outdoor access to pasture ranks first, followed by any outdoor access to straw bedding. The results can make a significant contribution to future communication with critical consumers concerning the implementation of higher animal welfare levels, as it becomes clearer how realistic consumers are about the feasibility of several animal welfare measures. Furthermore, the results could prove useful for the design of animal welfare programs and could help famers making targeted decisions concerning stable construction and management.
\end{abstract}

Keywords Animal welfare $\cdot$ Consumer analysis $\cdot$ Consumer communications, pig farming

\section{Introduction}

The meat industry is still in an international market and Germany is indispensably dependent on the export of pork (VDF/BVDF 2019). According to the Food and

Sirkka Schukat

Sirkka.schukat@uni-goettingen.de

1 Department of Agricultural Economics and Rural Development, Georg-August-University Göttingen, 37073 Göttingen, Germany 
Agriculture Organization (FAO), around 121 million tons of pork were produced worldwide in 2018. In terms of export volume, after China and the USA, Germany is the world's largest exporter with nearly 3.5 million tons of produced pork per year (FAO 2018). Particularly in northwestern European countries, there are strong social discussions about the produced pork regarding animal welfare in livestock farming. The issue of farm animal welfare (FAW) has become increasingly important for society. Food producers are permanently challenged, because consumer demands are changing fast and require a maximum of flexibility due to increasing economic pressure.

In response, the European Union and many national governments have strengthened regulations to ensure a higher level of welfare for farm animals. It is therefore necessary to develop farming concepts for pig farming that are both socially acceptable and practically feasible. Social criticism of the legal standards in pig farming and the resulting willingness of livestock farmers to respond appropriately by investing in more animal-friendly pigsties often counteracts the profitability of the farms (Grethe 2017). In addition to economic efficiency, the practical implementation of the necessary animal welfare measures is often not easily achieved (Wellner et al. 2019). Safety at work and labor time requirements for higher animal welfare standards as well as the approval of new pigsties or reconstructions often cause major challenges for farmers (Scholz 2015; Herrmann 2019a)

Pig farmers in particular are confronted with the challenge of harmonizing society's expectations, economic and technical aspects and any conflicting objectives that may emerge (see Grethe 2017; Dawkins 2017). Consumers may not be aware of the barriers related to the implementation of certain FAW measures and therefore may not understand why certain animal welfare measures have not (yet) been implemented on pig farms (Cornish et al.2019; Gross and Roosen 2017; Tomasevic et al. 2020).

Pig farmers are basically willing to consider consumers' wishes in their future pigsties with improve animal welfare (Latacz-Lohmann and Schreiner 2019; von Meyer-Höfer et al. 2019; Platto et al. 2020). Given that consumers are not experts in pig farming, we put forward the hypothesis that consumers assess the practicability of animal welfare measures rather high than low and higher than pig farmers and researchers.

The aim of this study is to analyze consumers' perceptions of different animal welfare measures. We are investigating which animal welfare measures and construction elements are considered important and feasible from the consumers' perspective in the planning of future pigsties. Therefore 1101 consumers were surveyed by means of a standardized online survey to assess firstly the relevance of 33 different animal welfare measures in future pigsties in October 2018. Secondly, the questioned consumers had to evaluate the feasibility of those animal welfare measures for pig farmers. Consumers' demands for future pigsties are widely known (Simons et al. 2018; von Meyer-Höfer et al. 2019). Less well known, however, is how easy or difficult it would be for pig farmers from the consumer's point of view to implement animal welfare measures (Heise and Theuvsen 2017; von Meyer-Höfer et al. 2019). The results can assist farmers to better understand consumers' preferences and at the same time demonstrate how consumers judge the feasibility of certain animal welfare measures. Pig farmers when designing future pig housing systems should include the measures considered important. Moreover, farmers could offer to adapt the design of their future pigsties, if animal welfare measures which are considered difficult to implement by consumers are in fact easier to adopt in practice. 


\section{Material and Methods}

\section{Sampling and Study Design}

Quantitative data was collected through a questionnaire-based consumer survey in a representative sample of consumers in Germany. Data collection was performed by an online panel provider in October 2018. A total of 1.101 consumers were recruited. The questionnaire was available online and the participation was anonymous. Online-based surveys are considered a cost-efficient, effective and time-saving method of data collection (Fricker and Schonlau 2002; Wright 2005; Wagner and Hering 2014). In order to represent the average German population, a quota sampling procedure, with gender, age, educational level and number of inhabitants of the place of residence was applied. This corresponds with the 2018 data of the Federal Statistical Office, which refer to the year 2017 (see Table A1).

The questionnaire was originally developed in German and then translated into English for the analyses. It was pre-tested with a small group of volunteers, who were explicitly asked to comment on the clarity of the questions. The survey questions mainly consisted of closed questions to be answered on five-point Likert scales. Participants answered a total of 45 questions regarding socio-demographic variables, about agricultural knowledge, one's own information about meat and meat product consumption and in focus about various housing construction and management elements of conventional German pig farming. The present paper focuses on assessing importance and feasibility of housing construction and management elements in future pigsties. Respondents were asked to specify on a five-point Likert scale ( $1=$ "not at all important"; $5=$ "very important") how important they considered 33 animal welfare measures (see Table 1) to improve FAW and what they think how feasible the measures for pig farmers are ( 1 = "not at all feasible"; 5 = "very feasible"). The questions the consumers had to answer were "Imagine an animal-friendly pigsty of the future. How important are the following animal welfare measures in pig farming" and "How do you assess the practical feasibility of the following animal welfare measures in pigsties in Germany?". The questionnaire did not further define "importance" and "feasibility". Exactly the same 33 animal welfare measures had to be evaluated for each of the two questions. The 33 measures were developed within the framework of a previous research project ("Virtual stall of the future") in discussions with consumers (von Meyer-Höfer et al. 2019). The individual measures were not defined in the questionnaire. As in public discussions, consumers hear or read the terms and are not thoroughly informed. For this reason, the meaning of the measures presented was deliberately transferred to the subjective interpretation of the individual persons. Otherwise the respondents would have an advance in knowledge and would no longer represent the German population.

Prior to the analysis a quality check was performed with the data set. In accordance with the recommendations of Wagner and Hering (2014), the data set was checked for missing values, response patterns, inconsistent responses and outliers.

\section{Analysis Methods}

Statistical analysis was performed using IBM SPSS Statistics 26 statistical program. Descriptive and univariate analyses were applied for the evaluation of the perceived 
Table 1 Participants' agreement with importance and feasibility of 33 animal welfare measures

\begin{tabular}{|c|c|c|c|}
\hline No. & Animal welfare measure & Importance mean (SD) & Feasibility mean (SD) \\
\hline 1 & Various functional areas (e.g. feeding. resting. fecal area) & $4.35^{\mathrm{a}}(0.758)$ & $3.24^{\mathrm{b}}(0.971)$ \\
\hline 2 & Outdoor access consists of concrete & $2.92^{\mathrm{a}}(1.046)$ & $3.34^{\mathrm{b}}(0.896)$ \\
\hline 3 & Outdoor access to straw bedding & $4.03^{\mathrm{a}}(0.839)$ & $3.48^{\mathrm{b}}(0.871)$ \\
\hline 4 & Outdoor access to pasture & $4.46^{\mathrm{a}}(0.749)$ & $3.36^{\mathrm{b}}(1.079)$ \\
\hline 5 & Sand bedding (complete barn) & $3.52^{\mathrm{a}}(0.934)$ & $3.45^{\mathrm{b}}(0.947)$ \\
\hline 6 & Sand bedding (single pens) & $3.75^{\mathrm{a}}(0.881)$ & $3.59^{\mathrm{b}}(0.852)$ \\
\hline 7 & Outdoor climate housing system & $3.88^{\mathrm{a}}(0.930)$ & $2.95^{\mathrm{b}}(0.939)$ \\
\hline 8 & Low emissions & $3.57^{\mathrm{a}}(0.891)$ & $2.77^{\mathrm{b}}(0.897)$ \\
\hline 9 & Optimum climate in the barn for the pigs & $4.32^{\mathrm{a}}(0.715)$ & $3.25^{\mathrm{b}}(0.893)$ \\
\hline 10 & Abandonment of slatted floor & $3.84^{\mathrm{a}}(1.007)$ & $3.17^{\mathrm{b}}(0.979)$ \\
\hline 11 & Bright barns with large windows & $4.26^{\mathrm{a}}(0.755)$ & $3.27^{\mathrm{b}}(0.951)$ \\
\hline 12 & Group housing sows and piglets & $3.87^{\mathrm{a}}(0.876)$ & $3.42^{\mathrm{b}}(0.882)$ \\
\hline 13 & Stopping fixation of sows during the farrowing period & $3.87^{\mathrm{a}}(0.904)$ & $3.54^{\mathrm{b}}(1.024)$ \\
\hline 14 & Opportunity to perform cleaning behavior (wallowing) & $4.48^{\mathrm{a}}(0.682)$ & $3.48^{\mathrm{b}}(0.934)$ \\
\hline 15 & Access to manipulable material & $3.82^{\mathrm{a}}(1.066)$ & $3.83^{\mathrm{b}}(1.054)$ \\
\hline 16 & Constant access to roughage & $4.23^{\mathrm{a}}(0.717)$ & $3.96^{\mathrm{b}}(0.866)$ \\
\hline 17 & Drinking from an open water source & $3.94^{\mathrm{a}}(0.904)$ & $3.63^{\mathrm{b}}(0.963)$ \\
\hline 18 & Greening inside the barn & $3.29^{\mathrm{a}}(1.055)$ & $2.96^{\mathrm{b}}(1.042)$ \\
\hline 19 & Group sizes of a maximum of 20 pigs & $4.20^{\mathrm{a}}(0.767)$ & $3.31^{\mathrm{b}}(1.005)$ \\
\hline 20 & Straw bedding (complete barn) & $3.88^{\mathrm{a}}(0.889)$ & $3.60^{\mathrm{b}}(0.949)$ \\
\hline 21 & Straw bedding (single pens) & $4.08^{\mathrm{a}}(0.785)$ & $3.76^{\mathrm{b}}(0.897)$ \\
\hline 22 & Changing breeding to robust pig breeds & $3.52^{\mathrm{a}}(0.962)$ & $3.05^{\mathrm{b}}(0.819)$ \\
\hline 23 & Support of comfort behavior (opportunity to wallow) & $4.42^{\mathrm{a}}(0.732)$ & $3.46^{\mathrm{b}}(0.942)$ \\
\hline 24 & Animal-friendly interaction & $4.67^{\mathrm{a}}(0.574)$ & $4.02^{\mathrm{b}}(0.961)$ \\
\hline 25 & Regular animal monitoring by the farmer & $4.44^{\mathrm{a}}(0.674)$ & $3.78^{\mathrm{b}}(0.949)$ \\
\hline 26 & Well-trained staff & $4.51^{\mathrm{a}}(0.661)$ & $3.40^{\mathrm{b}}(0.958)$ \\
\hline 27 & Low use of antibiotics & $4.38^{\mathrm{a}}(0.790)$ & $3.45^{\mathrm{b}}(1.037)$ \\
\hline 28 & Complete renunciation of the use of antibiotics & $4.03^{\mathrm{a}}(0.920)$ & $3.23^{\mathrm{b}}(1.145)$ \\
\hline 29 & Stopping grinding piglets' canines & $3.71^{\mathrm{a}}(0.994)$ & $3.71^{\mathrm{b}}(1.038)$ \\
\hline 30 & Stopping tail docking & $4.02^{\mathrm{a}}(0.949)$ & $3.87^{\mathrm{b}}(1.012)$ \\
\hline 31 & Transparency of husbandry conditions & $4.33^{\mathrm{a}}(0.772)$ & $3.73^{\mathrm{b}}(0.942)$ \\
\hline 32 & Accessibility to the public & $3.41^{\mathrm{a}}(1.173)$ & $3.22^{\mathrm{b}}(1.147)$ \\
\hline 33 & No sow-fixation for the protection of piglets & $3.80^{\mathrm{a}}(0.908)$ & $3.55^{\mathrm{b}}(0.993)$ \\
\hline
\end{tabular}

a Scale for importance from $1=$ not at all important to $5=$ very important

b Scale for feasibility of implementing from $1=$ "very difficult to implement" to $5=$ "very easy to implement" Standard deviation $(S D)$ : the higher $\mathrm{SD}$, the more disunited the respondents are. $n=1048$

Source: Author's calculation

importance and feasibility of the various animal welfare measures in order to gain an overview of the attitudes of the respective consumers (Backhaus et al. 2011). Mean values of the data were then calculated for the analysis. This approach allows to include a large amount of FAW measures and to identify the relevant measures. A system of coordinates was set up to graphically analyze the mean values of the assessments of importance and feasibility of the respective measures in relation to each other. Using this so called "four-field matrix", the mean values of both the perceived importance and the feasibility of the 33 animal welfare measures surveyed were combined and graphically displayed (see Fig. 1). Four possibilities are visualized: important-easy to implement, important-not feasible, not important-easy to implement and not important-not feasible. If all mean values are classified the assessment of the respective measure can be clearly seen. 


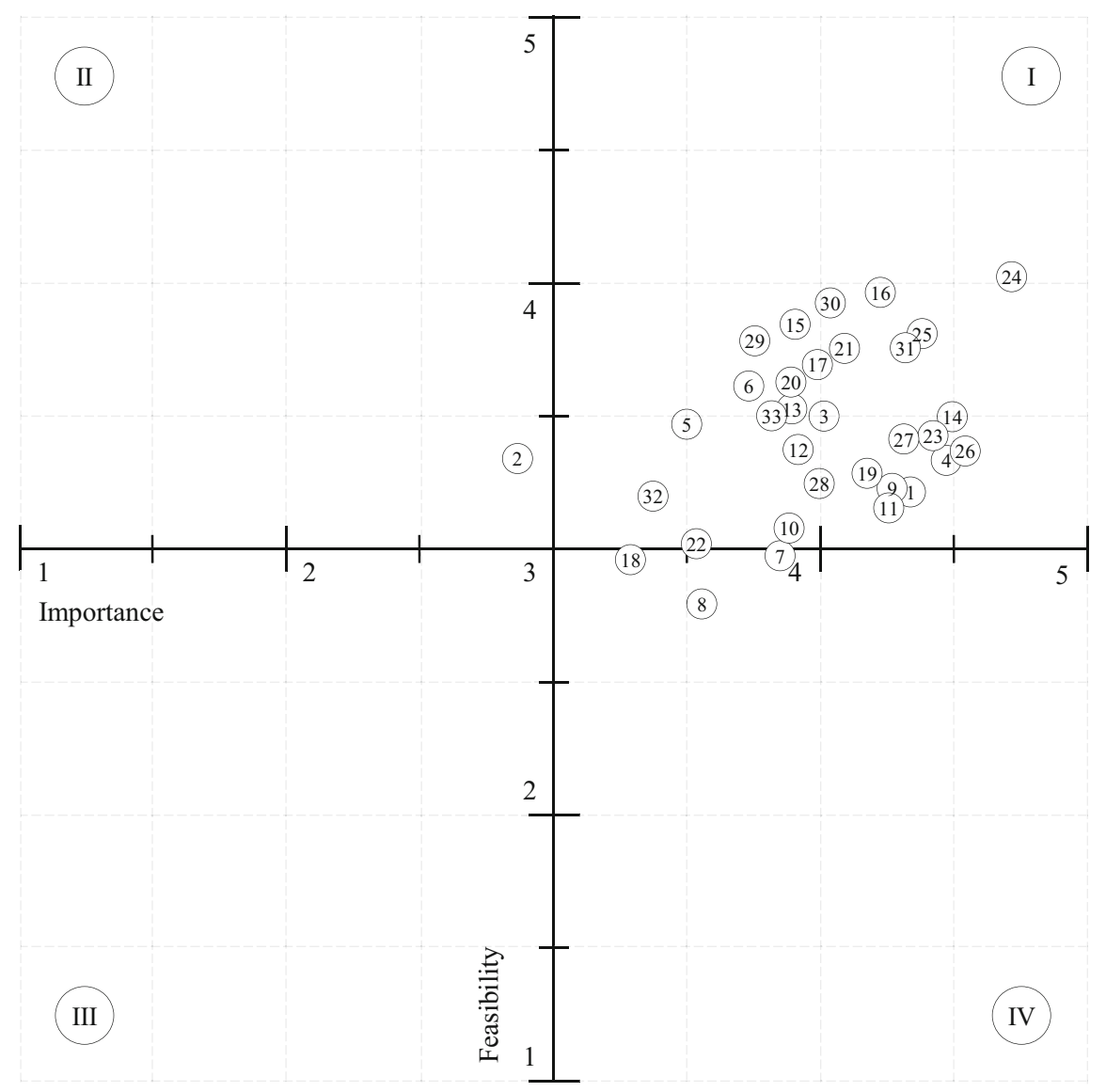
(1) Various functional areas (e.g. feeding, resting, fecal area)
(18) Greening inside the barn
(2) Outdoor access consist of concrete
(19) Group sizes of a maximum of 20 pigs
(3) Outdoor access to straw bedding
(20) Straw bedding (complete barn)
(4) Outdoor access to pasture
(5) Sand bedding (complete barn)
6) Sand bedding (single pens)
(7) Outdoor climate housing system
(8) Low emissions
(9) Optimum climate in the barn for the pigs
(21) Straw bedding (single pens)
(10) Renunciation of slatted floor
(11) Bright barns with large windows
(12) Group housing sows and piglets
(13) Renunciation of the fixation of sows during the farrowing period
(22) Changing breeding to robust pig breeds
(23) Support of comfort behavior (opportunity to wallow)
(14) Opportunity to perform cleaning behavior (wallowing)
(24) Animal-friendly interaction
(25) Regular animal monitoring by the farmer
(26) Well-trained staff
(27) Low use of antibiotics
(15) Access to manipulable material
(28) Complete renunciation of the use of antibiotics
(29) Renunciation of grinding the canines of piglets.
(30) Renunciation of tail docking
(16) Constant access to roughage
(31) Transparency on husbandry conditions
(32) Accessibility to the public
(17) Drinking from an open water source
(33) No sow-fixation for the protection of piglets

Fig. 1 Four-field matrix displaying the importance and feasibility of animal welfare measures from the consumers' point of view (Source: Authors illustration). Scale for importance from $1=$ not at all important to $5=$ very important. Scale for feasibility of implementing from $1=$ "very difficult to implement" to $5=$ "very easy to implement". Thirty three queried FAW measures. $n=1048$ 


\section{Results}

\section{Sample Description}

After exclusion of 53 questionnaires because of incompleteness, response patterns, inconsistent responses and outliers, 1048 completed questionnaires remained for the analysis. Respondents were between 18 and 69 years old (mean 45 years). Of the respondents, $48.8 \%$ were women, and $51.1 \%$ were men. $0.1 \%$ were other survey participants. Table A1 describes the sociodemographic distribution of participants and compares it with available data of the general population in Germany. Compared to the statistics of the Federal Statistical Office (2019a, b), there is only a slightly deviation from the German national average (48.8\% male, $51.2 \%$ female, average age: 44 years). Most respondents (58.9\%) live in cities with more than 20,000 inhabitants. Likewise, $59.4 \%$ of Germans live in municipalities of that size or larger (German Federal Statistical Office 2019c). This study is representative for the German population, as the deviations are marginal.

The net income of $19.8 \%$ of respondents is less than $€ 1300$ (per month). Most respondents (32.6\%) have an income between $€ 1300$ and $€ 2600.20 \%$ earn between $2600 €$ and $3600 €$ and $17.2 \%$ of respondents earn more than $3600 € .10 .8 \%$ did not give a statement. When asked about what extent the participants know about meat production, a strong tendency towards the Likert scales' middle is evident. $1.9 \%$ describe themselves as very well informed and $12.7 \%$ as rather well informed. $50.7 \%$ of all respondents consider themselves moderately informed. $29.3 \%$ feel rather poorly informed about meat production and $5.3 \%$ of the participants regard themselves as not informed at all. Respondents were also questioned about their state of knowledge in agriculture. The results are very similar to those of the assessment of the own state of knowledge on meat production.

\section{Importance of Selected Animal Welfare Measures}

Table 1 shows the response behavior of the consumers surveyed. The mean values (importance) of the individual animal welfare measures range between 2.92 ("outdoor access consists of concrete") and 4.67 ("animal-friendly interaction"). Overall, the measures "outdoor access consists of concrete" $(\mu=2.92 ; \mathrm{SD}=1.046)$, "greening inside the barn" $(\mu=3.29$; $\mathrm{SD}=1.055)$ and "accessibility to the public" $(\mu=3.41 ; \mathrm{SD}=1.173)$ are assessed as "partial". The standard deviations are also given in Table 1. High standard deviations (in particular values higher 1) indicate that respondents expressed quite inconsistent opinions about the given categories. Especially in the category "accessibility to the public" analysis shows a high standard deviation. "Well-trained staff" $(\mu=4.51 ; \mathrm{SD}=0.661)$ and "animal-friendly interaction" ( $\mu=4.65 ; \mathrm{SD}=0.574)$ are the both most important animal welfare measures and are ranked as "very important". All other aspects (28) are on average perceived as "important". The results are therefore all in a relatively similar range. The "opportunity to perform cleaning behavior (wallowing)" ( $\mu=4.48 ; \mathrm{SD}=0.682)$ in future barns is perceived as being of great importance. The "regular animal monitoring by the farmer" $(\mu=4.44 ; \mathrm{SD}=0.674)$ is also considered relevant. It becomes apparent that the staff in pigsties is important with regard to animal welfare for the consumers. A reduction in the use of antibiotics is more important $(\mu=$ 4.38; $\mathrm{SD}=0.790)$ than complete renunciation of the use of antibiotics $(\mu=4.03 ; \mathrm{SD}=0.920)$. The evaluation of the use of antibiotics is therefore not completely rejected, although the difference in the evaluation is marginal. With regard to straw bedding, it appears that 
consumers consider straw bedding in "single pens" $(\mu=4.08$; $\mathrm{SD}=0.785)$ to be slightly more important than straw bedding in the "complete barn" $(\mu=3.88 ; 0.889)$. Sand bedding is rated less important than straw bedding (single pens $\mu=3.75$; $\mathrm{SD}=0.881$; complete barn $\mu=3.52$; $\mathrm{SD}=0.934)$. Consumers assess the measure "greening inside the barn" $(\mu=3.29 ; \mathrm{SD}=1.055)$ neither as particularly important nor as very unimportant. Again, the standard deviation is relatively high, which means that the respondents were not very unanimous. All in all consumers classify almost all FAW measures examined as "important" or "very important" for improving FAW.

\section{Feasibility of Selected Animal Welfare Measures}

In a second question, respondents were also asked to use five-point Likert scales to assess how easily they think animal welfare measures can be implemented for farmers in pigsties. The scale ranged from 1 = "very difficult to implement" to $5=$ "very easy to implement". The mean values of the sample vary between 2.77 ( $\mathrm{SD}=0.897$; "low emissions") and 4.02 ( $\mathrm{SD}=0.961$; "animal-friendly interaction"). Of the 33 animal welfare measures questioned, 20 are assessed as "feasible" $(\mu=2.77$ to $\mu=3.48)$ and $13(\mu=3.54$ to $\mu=4.02)$ as "easily implementable". "Animal-friendly interaction" $(\mu=4.02 ; \mathrm{SD}=0.961)$, "constant access to roughage" $(\mu=3.96$; $\mathrm{SD}=0.866)$ and "stopping tail docking" $(\mu=3.87 ; \mathrm{SD}=1.012)$ are rated as the measures easiest to implement. The respondents were less in agreement on "stopping tail docking" that on "constant access to roughage".

The respondents assess "low emissions" $(\mu=2.77$; $\mathrm{SD}=0.897)$, "outdoor climate housing system" ( $\mu=2.95 ; \mathrm{SD}=0.939)$ and "greening inside the barn" $(\mu=2.96 ; \mathrm{SD}=1.042)$ as more complicated for the farmer to implement and assess these three measures as partially implementable. For both sand $(\mu=3.45 ; \mathrm{SD}=0.947)$ and straw $(\mu=3.60 ; \mathrm{SD}=0.949)$ bedding, respondents consider it easier to carry out complete bedding of the barn than single pens. The bedding of single pens for sand $(\mu=3.59$; $\mathrm{SD}=0.852)$ and straw $(\mu=3.76$; $\mathrm{SD}=0.897)$ is answered as more complicated to implement. "Outdoor access to pasture" $(\mu=3.36 ; \mathrm{SD}=$ $1.079)$ is considered easier to implement than outdoor access on concrete $(\mu=3.34 ; \mathrm{SD}=$ $0.896)$ or on a paved area with straw bedding $(\mu=3.48 ; \mathrm{SD}=0.871)$. "Constant access to roughage" $(\mu=3.96 ; \mathrm{SD}=0.866)$ or "access to manipulable material" $(\mu=3.83 ; \mathrm{SD}=1.054)$ are among the measures considered feasible, but more complicated to implement than other measures. The mean values and standard deviations are listed in Table 1. In summary, the high standard deviations are conspicuous in almost all evaluations.

\section{Importance and Feasibility of Selected Animal Welfare Measures}

In order to graphically illustrate the different consumers' assessments of the importance and feasibility of animal welfare measures and to derive which animal welfare measures are potentially most important for inclusion in future pigsties and to get an overview, how easy or difficult consumers consider the implementation, a four-field matrix was created (Fig. 1). With regard to practicability, the mean values are slightly lower compared to the importance rating overall.

In the first quadrant, there are the animal welfare measures, which are rated positively by the consumers surveyed with regard to both importance and feasibility. The measures in the first quadrant are various functional areas $(\mu=4.351$ importance, $\mu=3.242$ feasibility), outdoor access to straw bedding $(\mu=4.031, \mu=3.482)$ and outdoor access to pasture 
( $\mu=4.461, \mu=3.362)$. Also sand bedding in the complete barn $(\mu=3.521, \mu=3.452)$, sand bedding in single pens $(\mu=3.751, \mu=3.592)$, straw bedding (complete barn) $(\mu=3.881, \mu=$ 3.602), straw bedding (single pens) $(\mu=4.081, \mu=3.762)$ and abandonment of slatted floor $(\mu=3.841, \mu=3.172)$ are judged as important and feasible. An optimum barn climate for the pigs $(\mu=4.321, \mu=3.252)$, bright barns with large windows $(\mu=4.261, \mu=3.272)$, constant access to roughage $(\mu=4.231, \mu=3.962)$, drinking from an open water source $(\mu=3.941, \mu=$ 3.632 ), opportunity to perform cleaning behavior (wallowing) ( $\mu=4.481, \mu=3.482$ ) and the access to manipulable material $(\mu=3.821, \mu=3.832)$ are located in the first quadrant. Also included are the measures group housing sows and piglets $(\mu=3.871, \mu=3.422)$, group sizes of a maximum of 20 pigs $(\mu=4.201, \mu=3.312)$ and no sow-fixation for the protection of piglets $(\mu=3.801, \mu=3.552)$. The support of comfort behavior (opportunity to wallow) $(\mu=$ $4.421, \mu=3.462)$, animal-friendly interaction $(\mu=4.671, \mu=4.022)$, regular animal monitoring by the farmer $(\mu=4.441, \mu=3.782)$, well-trained staff $(\mu=4.511, \mu=3.402)$, transparency of husbandry conditions $(\mu=4.331, \mu=3.732)$ and accessibility to the public $(\mu=3.411$, $\mu=3.222)$ are located in the first quadrant. The low use of antibiotics $(\mu=4.381,3.452)$, complete abandonment of the use of antibiotics $(\mu=4.031, \mu=3.232)$, changing breeding to robust pig breeds $(\mu=3.521, \mu=3.052)$, stopping grinding piglets' canines $(\mu=3.711, \mu=$ 3.712), stopping tail docking $(\mu=4.021, \mu=3.872)$ and stopping fixation of sows during the farrowing period $(\mu=3.871, \mu=3.542)$ are assessed as important and feasible and as a consequence in quadrant I. All these measures are judged as important and feasible for future pigsties from the consumers' point of view.

In the second quadrant, there is the animal welfare measure "outdoor access consists of concrete" ( $\mu=2.921, \mu=3.342)$ that is classified as less important but is perceived as quite feasible. From the consumer's perspective, they could be implemented in pigsties without much additional effort, but these measures are not very relevant for consumer acceptance, as they were answered to be relatively insignificant. In this study the third quadrant does not include any animal welfare measures. The fourth quadrant contains the animal welfare measures outdoor climate housing system $(\mu=3.881, \mu=2.952)$, low emissions $(\mu=3.571$, $\mu=2.772)$ and greening inside the barn $(\mu=3.291, \mu=2.962)$, which were rated positively in terms of importance, but received negative evaluations with regard to practical feasibility. As a result, the respondents consider the implementation of these three measures to be more challenging. They might be aware, for example, that reducing emissions is a greater challenge than the other measures but on the scale a mean of 2.77 still means "partial feasible".

\section{Discussion}

The debate on livestock farming and consumer preferences in relation to agriculture has been a challenge for some time. Consumers demand FAW, but conventional farmers often cannot profitably afford higher animal welfare measures (Grethe 2017). A current challenge is to achieve consensus on the design of future pig housing systems to meet the wishes of farmers and consumers (Lassaletta et al. 2019; Turner et al. 2018; von Meyer-Höfer et al. 2019). Twenty five years ago, society and politics demanded one thing above all from pig farmers: international competitiveness (Hörning 2019). The pig farmers adjusted to this and responded by producing at minimum cost level. They succeeded in compensating for the higher labor costs in Germany through higher productivity in order to remain internationally competitive (Dierauff 2019). The consequence was a considerable structural change that resulted in larger 
farms and production units (Dierauff 2019). A few years later, an increasingly intense debate on environmental and animal protection developed in the media and politics.

The assessments of the $n=1.048$ consumers surveyed are discussed based on a literary research with scientific findings of FAW in pig farming. It is evident that there is a latent emotional unease in the population about the current form of conventional pig farming. When answering the question of importance, almost all measures are rated as "important". In addition, feasibility is generally rated as "rather easy to implement". Farm animals are often equated with pets by society (Simons et al. 2018). This leads to a humanization of the discussion on livestock husbandry in public, whereby the needs for animals are equated with those of humans (Scholz 2004). Consumers evaluate results of science on animal husbandry on the basis of their personal attitudes and feelings.

Consumers rate the avoidance of slatted floors as important $(\mu=3.84)$ and feasibility $(\mu=3.17)$ as partly practicable. However, pig farmers have to completely rearrange the manure removal in their pigsties if they do not utilize slatted floors (Jais et al. 2016). Nevertheless, technical solutions already exist on the market (Hölscher and Leuschner 2019). Farmers should also consider separating feces and urine to reduce the formation of ammonia (Döhler et al. 2019). This would also require a change in the manure removal process. Moreover, straw bedding would impose different manure removal requirements than strawless bedding. However, precisely this aspect (straw bedding) is also considered important. Images of the animals kept on straw bedding may be perceived as more sympathetic and natural, which provides additional evidence of the effectiveness of the so-called natural bias (Busch et al. 2017). Science also addresses the experience that moderate bedding influences the behavior of pigs (Munsterhjelm et al. 2009). When assessing production processes, nature is often the measure of all things (cf. Clark et al. 2016). Researchers (EIP-AGRI 2018) analyze the effects of "greening inside the barn" $(\mu=3.29)$ on emissions and air quality in pigsties. Greening within barns, however, is classified as slightly less important $(\mu=3.29)$ compared to other animal welfare measures investigated, although it could also be associated with naturalness. Here the comparatively high standard deviation of 1.055 should be mentioned. It means that the respondents were rather divided in their assessment of this measure. Rozin (2005) investigated the manifestations and psychological causes of this preference for naturalness. He referred to the following example: the naturalness preference might partly explain why keeping pigs free-range peaks when the advantages and disadvantages of agricultural technologies were questioned - an assessment that is not shared by other experts (Boogaard et al. 2011; Rozin 2005).

Also in the present survey, the importance of access to pasture $(\mu=4.46)$ is significantly higher than an access to a paved area $(\mu=2.92)$. The feasibility of both measures is assessed almost identically $(\mu=3.36$ and $\mu=3.34)$. From a farmer's point of view, however, the implementation is much more complicated with regard to permits and conflicts of objectives with climate and environmental protection, especially for pasture (Keck and Schrade 2014; Mielke et al. 2015; Vermeer and Hopster 2018). However, the high standard deviation of 1.079 when assessing the feasibility of this measure must also be taken into account. The respondents agree on one point: they consider animal-friendly interaction to be the most important $(\mu=4.67)$ and also rate its feasibility $(\mu=4.67)$ as the highest. The Federal Ministry of Justice and Citizen Protection (2019) also includes this aspect and it should therefore be taken for granted. However, today's treatment of animals often does not correspond to ideas of morality, liberality and sensitivity from a 
social and animal ethics perspective (Clark et al., 2016; Precht 2016). The employment of well-trained staff, which the respondents also considered very important, is considered more difficult to implement. There is indeed a shortage of skilled workers in German agriculture (Rolink 2019). The promotion of skilled workers would therefore be important for communication with society on the part of agriculture.

Furthermore, the respondents consider it relatively easy to refrain from tail docking $(\mu=$ 3.87). For pig farmers, however, this measure is difficult to implement in existing housing systems in the EU without changing the framework conditions (D'Earth et al. 2016). These include space required per animal, the pigs' breed or soil conditions if injuries to the pigs are to be excluded (Schneider 2013). In the absence of docking the tail, research has shown that $81 \%$ of pigs had tail injuries at the time of slaughter (Blaha et al. 2014). In 2016, more than 30 different projects investigated possibilities to make tail docking redundant (Wehmeier-Graf 2016). Not only shortened tails but also the reduction or abolition of antibiotics can result in serious animal welfare problems. A poor state of health would be a possible consequence of skipping the antibiotic treatment that is not beneficial to animal welfare (Sundrum 2015). For consumers, a reduced usage of antibiotics $(\mu=4.38)$ is more important than a complete abstinence $(\mu=4.03)$. Also in terms of practicability, a possible reduction $(\mu=3.45)$ is considered more feasible than complete renunciation $(\mu=3.23)$. This path of compromise must be broadly achieved in the current transition to future pig farming. However, standard deviations are high, both in the assessment of the reduction $(\mathrm{SD}=1.037)$ and complete renunciation $(\mathrm{SD}=1.145)$ of antibiotics, i.e. there was disagreement among the respondents (Dee et al. 2018).

Also important for the health of the pigs is an optimal climate in the barn. In consumers' priority order of importance, an optimal barn climate $(\mu=4.32)$ and various functional areas for the pigs $(\mu=4.35)$ are relatively high. However, feasibility is considered more difficult $(\mu=3.25$ and $\mu=3.24)$. Since an optimal climate is a basic requirement for the health of pigs, special ventilation systems have long been used to ensure good air circulation in pigsties (Yeo et al. 2019; Wenke et al. 2018). Furthermore, different functional areas have already been added in many pigsties (Feller 2019). It should be more explicitly communicated that this step is more feasible for farmers than expected. Moreover, there are also other animal welfare measures which many farmers in Germany are willing to implement in their barns. In some parts of Germany, however, they are often constrained by environmental legislation. This often affects the enlargement of farrowing pens, for example when altering existing barn facilities. In many cases, farmers do not receive a construction permission for such measures because animal protection legislation and building regulations do not go hand in hand (Herrmann 2019b). This includes, among other things, the Federal Building Law and Technical Instructions on Air Quality Control ("TA Luft") in Germany, which particularly affect pig farmers in the livestock-strong regions of northwestern Germany. It is conceivable that this conflict of objectives is not apparent to consumers and should be communicated more explicitly in the media, for example. Indeed, many consumers would wish for a different way of livestock farming, but not in the immediate vicinity of their homes and without harming the environment (Clark et al. 2016). According to Herrmann (2019b), these restrictive construction permissions are accompanied by uncertainty about the maintenance and continuation of agricultural operations and ongoing public critique. 
Consumers' desire to see pigs in the natural environment is often constrained by legal regulations. Free range husbandry is not compatible with emission regulations in some parts of Germany (DBV 2017; Vermeer and Hopster 2018). Alarmingly, pigs do not like bright sunlight and prefer subdued light (DLG 2017). In addition, pigs quickly get sunburned. This fact might also not be obvious to every consumer. Consumers, on the other hand, wish brighter barns with large windows for pigs $(\mu=4.26)$. They estimate feasibility costs to be lower than for other animal welfare measures examined $(\mu=3.27)$. Farmers and consumers perceive situations differently, which was found in a study by Busch et al. (2017). Discrepancies occur in perception, especially in relation to natural behavior, stress, space and pain (Vanhonacker et al. 2008; Garforth et al. 2013).

The classification of the importance of selected animal welfare measures and consumer perceptions regarding the feasibility of animal welfare measures were analyzed in this study and contrasted in the discussion with assessments of these measures from other literature and experts. The results serve as an orientation guide for pig farmers, stall construction companies as well as for association of pig farmers and politics. On the one hand, pig farmers could attempt to take into account the classification of the importance of the measures by consumers in their future pigsties in order to increase social acceptance. Some measures may be easier to implement than for example German agricultural newspapers often communicate (Döhler 2019). On the other hand, explanations should be provided for those animal welfare measures that are easy to implement from the consumers' point of view but which are not practicable for the farmer for various reasons, such as authorization procedures, cost-effectiveness or practical implementation. This communication could originate from farmers, representatives of the agricultural sector (e.g. staff of chambers of agriculture) or associations of pig farmers.

Like most studies, our research has some limitations that need to be considered when interpreting the results. The accuracy of the answers may be influenced by ideas of general beliefs or socially desirable responses, which is a common phenomenon in consumer science (Grunert and Wills 2007). To reduce socially desirable responding, we clarified to the participants that the participation in the study is anonymous and that there are no right or wrong answers (van Vaerenbergh and Troy 2013; Baumgartner and Steenkamp 2001). High standard deviations indicated that our group of consumers cannot be understood as one homogeneous group; there are subgroups that differ with regard to their attitudes toward importance and feasibility of FAW measures. These results are in line with the findings of Busch (2015), who also determined that there are different target groups among consumers in Germany. The results of our study reflect the attitude of the German population. This means that an insight into the international situation is not given. Despite the limitations mentioned above, the present study provides interesting results in an area of research that is highly relevant due to the social discussion.

In future research an international consumer survey could be conducted and evaluations of consumers of FAW measures of different countries could be compared. The long-term aim could be a comprehensive overview of the assessment of the importance and feasibility of consumers' point of view in different countries. In a first step only within Europe, in a second step a comparison between different continents could be carried out. As the meat sector is a global sector, similar FAW standards should apply in the long term, at least within Europe, and be equally accepted by consumers. However, first the implementation problems for each individual animal welfare measure should be 
identified and published in order to make it clear to consumers how difficult changes in animal husbandry can be for farmers.

\section{Conclusion}

This study examined the importance and feasibility of animal welfare measures from a consumer perspective $(n=1048)$ in Germany. Well-trained staff and animal-friendly interaction are the most important animal welfare measures. Consequently, from the consumer's point of view, the staff in pigsties have a significant influence on FAW. Further, no measure is rated as "very easy to implement". In addition, however, no measure is classified as "very difficult to implement". Animal-friendly interaction, constant access to roughage and stopping tail docking are judged by consumers to be the easiest measures to achieve.

$85.3 \%$ of consumers feel partially or not at all informed about meat production. Despite their missing knowledge about meat production and agriculture, they consider almost all animal welfare measures to be feasible. Other studies have shown, however, that not all animal welfare measures can be easily implemented (cf. chapter 4). Consumers often do not identify problems associated with the implementation of certain animal welfare measures. For future social acceptance of livestock farming, it is important to explain to consumers what the implementation challenges (e.g. on the company level, working hours, resources or due to difficulties in obtaining permits) are with individual animal welfare measures.

These implementation problems would need to be identified for each individual animal welfare measure in order to highlight to consumers how difficult changes in animal husbandry can be for farmers. Better communication with consumers can therefore address animal welfare measures where there are differences in opinion on practical implementation between the public and farmers. At this point the consumer must be educated so to gain an insight or understanding of the challenges of conventional pig farming in order to regain social acceptance. Communication rarely takes place directly between farmer and consumer. Therefore, association of pig farmers and politics could rather use the results for transparent communication.

Furthermore, these findings should be considered when developing future pigsties for the improvement of animal welfare in order to increase the likelihood that future pigsties will be accepted by the broader public. Especially improvements concerning handling animals need to be advertised and clearly communicated to the consumers, as handling-related aspects and staff training are important for many consumers. Consumers could be offered compromises by farmers if measures considered important were considered more difficult to implement than they actually are, and vice versa. For example, in the order of importance, an optimal indoor climate and different functional areas for the pigs are relatively high on the list of priorities. The feasibility, however, is classified as low. As an optimum climate is a basic requirement for pig health and various functional areas already exist in many pigsties, it may be necessary to communicate more explicitly that this step is more feasible for farmers than expected.

Acknowledgements We acknowledge support by the German Research Foundation and the Open Access Publication Funds of the Göttingen University.

Funding Open Access funding provided by Projekt DEAL. The study was financed by the "Stable of the Future" project of the German Federal Ministry of Food and Agriculture. 


\section{Appendix}

Table 2 Comparison of sample composition and basis population in Germany

\begin{tabular}{|c|c|c|}
\hline Variable & Survey & $\begin{array}{l}\text { Composition of the basic } \\
\text { population in Germany }\end{array}$ \\
\hline \multicolumn{3}{|l|}{ Gender in $\%$ a } \\
\hline Female & 51.1 & 51.2 \\
\hline Male & 48.8 & 48.8 \\
\hline Other & 0.1 & 0 \\
\hline \multicolumn{3}{|l|}{ Age in $\%$ a } \\
\hline $18-29$ & 21.2 & 14.2 \\
\hline $30-39$ & 17.7 & 11.8 \\
\hline $40-49$ & 18.7 & 16.6 \\
\hline $50-64$ & 32.9 & 20.4 \\
\hline $65-69$ or 74 (survey or germany) & 9.4 & 11.3 \\
\hline$\varnothing$ Age in years ${ }^{\mathrm{b}}$ & 45 & 44 \\
\hline \multicolumn{3}{|l|}{ Residence by population in $\% \mathrm{c}$} \\
\hline$<5.000$ & 14.3 & 14.2 \\
\hline $5.000-20.000$ & 26.8 & 26.4 \\
\hline $20.000-100.000$ & 27.1 & 27.5 \\
\hline$>100.000$ & 31.8 & 31.9 \\
\hline \multicolumn{3}{|l|}{ Educational Level in $\% \mathrm{~d}$} \\
\hline Still at school & 2.3 & 3.6 \\
\hline No school leaving certificate & 1.6 & 4.0 \\
\hline Lower or elementary secondary school leaving certificate & 32.7 & 30.4 \\
\hline Secondary or intermediate school leaving certificate or equivalent & 25.6 & 23.1 \\
\hline High school certificate & 37.8 & 31.9 \\
\hline
\end{tabular}

a Figures for basic population of Germany based on Federal Statistical Office of Germany (2019a)

${ }^{b}$ Figures for basic population of Germany based on Federal Statistical Office of Germany (2019b)

${ }^{c}$ Figures for basic population of Germany based on Federal Statistical Office of Germany (2019c)

d Figures for basic population of Germany based on Federal Statistical Office of Germany (2019d)

$n=1.048$

Source: Author's calculation

Open Access This article is licensed under a Creative Commons Attribution 4.0 International License, which permits use, sharing, adaptation, distribution and reproduction in any medium or format, as long as you give appropriate credit to the original author(s) and the source, provide a link to the Creative Commons licence, and indicate if changes were made. The images or other third party material in this article are included in the article's Creative Commons licence, unless indicated otherwise in a credit line to the material. If material is not included in the article's Creative Commons licence and your intended use is not permitted by statutory regulation or exceeds the permitted use, you will need to obtain permission directly from the copyright holder. To view a copy of this licence, visit http://creativecommons.org/licenses/by/4.0/.

\section{References}

Backhaus, Klaus, Bernd Erichson, Wulff Plinke, and Rolf Weiber. 2011. Multivariate analysis methods. Heidelberg: Springer.

Baumgartner, Hans, and Jan-Benedict Steenkamp. 2001. Response styles in marketing research: A cross-national investigation. Journal of Marketing Research 38 (2): 143-156. 
Blaha, Thomas, Meiners, Carolin, Tölle, Karl-Heinz Otto, Gerald. 2014. Final report of the re-port "testing of practicable solutions to avoid the tailing of tails in pigs with special regard to the economic consequences". http://www.ml.niedersachsen.de/portal/live.php?navigation_id=32027\&article_id=11087 2\&_psmand=7. Assessed 16 September 2019. (In German).

Boogard, Birgit Katharina, L.J.S. Boekhorst, Simon Oosting, and Jan Tind Sørensen. 2011. Socio-cultural sustainability of pig production: Citizen perceptions in The Netherlands and Den-mark. Livestock Science 140: $189-200$

Busch, Gesa. 2015. Animal husbandry and society. Communication management between agriculture and the public. Doctoral thesis. Georg-August-University Göttingen. Publisher Dr. Kovač, Hamburg, pp 1-326

Busch, Gesa, Sarah Gauly, and Achim Spiller. 2017. I spy with my little eye: An eye-tracking study regarding the perception and evaluation of pictures from pig fattening barns. German Journal of Agricultural Economics 66 (2): 65-84.

Clark, Beth, Garvin Stewart, Luca Panzonei, I. Kyriazakis, and Lynn Frewer. 2016. Systematic review of public attitudes, perceptions and behaviors towards production diseases associated with farm animal welfare. Journal of Agricultural and Environmental Ethics 29: 455. https://doi.org/10.1007/s10806-016-9615-x.

Cornish, Amelia, Brayden Ashton, David Raubenheimer, and Paul McGreevy. 2019. Australian consumers' knowledge and concern for animal welfare in food production: Influences on purchasing intentions. Society \& Animals 1 (aop): 1-28.

D’Eath, Rick, J.K. Niemi, B.V. Ahmadi, K.M.D. Rutherford, S.H. Ison, S.P. Turner, H.T. Anker, T. Jensen, M.E. Busch, K.K. Jensen, A. Lawrence, and P. Sandoe. 2016. Why are most EU pigs tail docked? Economic and ethical analysis of four pig housing and management scenarios in the light of EU legislation and animal welfare outcomes. Animal 10: 687-699.

Dawkins, Marian Stamp. 2017. Animal welfare and efficient farming: Is conflict inevitable? Animal Production Science 57 (2): 201-208.

DBV (German Farmers Association). 2017. Changes in livestock require feasibility and social consensus. https://www.bauernverband.de/veraenderungen-in-der-tierhaltung-erfordern-machbarkeit-undgesellschaftlichen-konsens. Accessed 3 September 2019. (In German).

Dee, Scott, Jose Guzman, Dan Hanson, Noel Garbes, Robert Morrison, Deborah Amodie, and Lucina Galina Pantoja. 2018. A randomized controlled trial to evaluate performance of pigs raised in antibiotic-free or conventional production systems following challenge with porcine reproductive and respiratory syndrome virus. PLoS One 13 (12): e0208430.

Dierauff, Jürgen. 2019. We need a national livestock strategy. “Agrarheute Schwein 12/19”. (In German).

DLG (Deutsche Landwirtschafts-Gesellschaft/ German Agricultural Society). 2017. DLG leaflet 420 - lighting technology for pigsties. https:/www.dlg.org/fileadmin/downloads/merkblaetter/dlg-merkblatt_420.pdf. Accessed 3 September 2019. (In German).

Döhler, Helmut. 2019. Animal welfare housing with lowest emissions. Concept study and first results. Presentation: Technical discussion about combining animal and immission control. Berlin: German Environmental Aid 20.01.2020. (In German).

EIP-AGRI. 2018. Projects of EIP-Agri in Germany. Innovative indoor greening systems in livestock farming to improve animal and environment protection (May 2018). https://eler-redaktion.ble.de/de/themen/eipagri/eip-datenbank/. Accessed 15 October 2020. (In German).

FAO (food and agriculture organization of the united nations). 2018. Livestock primary > Meat, pig. In: Official FAO production statistics for 2018. http://www.fao.org/faostat/en/\#data/QC. Accessed 03 Sept 2019

Federal Ministry of Justice and Consumer Protection. 2019. Animal welfare and animal husbandry ordinance (Tierschutz-Nutztierhaltungsverordnung). https://www.gesetze-im-internet.de/tierschnutztv/ BJNR275800001.html. Accessed 16 December 2019. (In German).

Federal Statistical Office of Germany. 2019a. Population (census): Germany, reference date, gender, age group. https://www-genesis.destatis.de/genesis//online/data?operation=table \&code=12111-0004\&levelindex=1 \&levelid=1574868982809. Accessed 23 November 2019. (In German).

Federal Statistical Office of Germany. 2019b. Population: Germany, cut-off date, age. https://www-genesis. destatis.de/genesis/online/link/tabelleErgebnis/12411-0005. Accessed 23 November 2019. (In German).

Federal Statistical Office of Germany. 2019c. Private households, household members: Germany, years, municipal size classes. https:/www-genesis.destatis.de/genesis//online/data?operation=table \&code=122110101\&levelindex $=0 \&$ levelid $=1574868562822$. Accessed 23 November 2019. (In German).

Federal Statistical Office of Germany. 2019d. Educational level. https://www.destatis.de/DE/ ZahlenFakten/GesellschaftStaat/BildungForschungKultur/Bildungsstand/Tabellen/Bildungsabschluss.html. Accessed 23 November 2019. (In German).

Feller, Bernhard. 2019. Overall farm management concept pig - fattening pigs. 16. KTBL-conference. https://www.ktbl.de/fileadmin/user_upload/Allgemeines/Download/Tagungen_2019/ARR/02_Feller.pdf. (In German). 
Fricker, Ronald, and Matthias Schonlau. 2002. Advantages and disadvantages of internet. Research surveys: Evidence from the literature. Field Methods 14 (4): 347-367.

Garforth, Chris, Alison Bailey, and Richard Tranter. 2013. Farmers' attitudes to disease risk management in England: A comparative analysis of sheep and pig farmers. Preventive Veterinary Medicine 110 (3-4): 456-466.

Grethe, Harald. 2017. The economics of farm animal welfare. Annual Review of Resource Economics 9: 75-94.

Gross, Sabine, and Jutta Roosen. 2017. Effects of information on trust in farmers regarding animal welfare. Paper prepared for presentation at the 2017. Chicago: Agricultural \& Applied Economics Association Annual Meeting.

Grunert, Klaus, and Josephine Wills. 2007. A review of European research on consumer response to nutrition information on food labels. Journal of Public Health 15 (5): 385-399.

Heise, Heinke, and Ludwig Theuvsen. 2017. Which animal welfare measures should be implemented in animal welfare programs? A stakeholder analysis. German Journal of Agricultural Economics 66 (4): 245-264.

Herrmann, Wiebke. 2019a. Uniform husbandry markings for meat now on the market. https://www.agrarheute. com/tier/einheitliche-haltungskennzeichnung-fuer-fleisch-handel-552820. Accessed 19 January 2020. (In German).

Herrmann, Wiebke. 2019b. Building law versus animal welfare. Agriculture today pig 2019 (Agrarheute Schwein) 08/19". (In German).

Hölscher, Richard and Leuschner, Werner. 2019. comfiFLOOR. The comfort floor for fattening pigs. https:/www.hl-agrar.de/cms/upload/Flyer/H_L_Flyer_ComfiFloor_D.pdf. Accessed 13 December 2019. (In German).

Hörning, Bernhard. 2019. "Factory farming" in Germany? An approximation. Meat. Nomos Verlagsgesellschaft mbH \& Co. KG. In: Fleisch. Vom Wohlstandssymbol zur Gefahr für die Zukunft. https://doi.org/10.5771 19783845284590-13. (In German).

Jais, Christina, Miriam Abriel, and Anja Müller. 2016. Five years of experiments involving piglets with undocked tails - consequences for the barn systems in breeding and fattening. Pork symposium. Annual Conference 2016. Conference proceedings, Ed. Bavarian State Institute for Agriculture, Ergolding.

Keck, Margret and Schrade, Sabine. 2014. Comparison of husbandry systems in terms of emissions and immissions. KTBL- expert discussion: Emission reduction and exhaust air purification. 11./12.9.2014. Hannover.

Lassaletta, Luis, FFernando Estellés, Arthur Beusen, Lex Bouwman, Salvador Calvet, Hans Van Grinsven, Jonathan Doelmana, Elke Stehfest, Aimable Uwizeye, and Henk Westhoek. 2019. Future global pig production systems according to the shared socioeconomic pathways. Science of the Total Environment 665: 739-751.

Latacz-Lohmann, U., and J.A. Schreiner. 2019. Assessing consumer and producer preferences for animal welfare using a common elicitation format. Journal of Agricultural Economics 70 (2): 293-315.

von Meyer-Höfer, Marie, Winkel, Carolin, Heise, Heinke, Schütz, Aurelia, Grimberg-Henrici, Chalotte, Krieter, Joachim, Gier, Nadine, Krampe, Caspar, Kenning, Peter, Tölle, Karl-Heinz, Hölscher, Richard and Spiller, Achim. 2019. Virtual stall of the future. From sows to fattening pigs - new stall construction concepts for pig farming in Germany with more animal welfare and acceptance. Results report. https://www.uni-goettingen. de/de/575789.html. Accessed 13 December 2019. (In German).

Mielke, Gesa, Ralf Bussemas, Marcus Clauß, Stefan Linke, Friedrich Weißmann, and Heiko Georg. 2015. The outside run area in the organic pig farm: Pollution distribution and ammonia emissions. Science Conference Organic Farming 13, Hochschule für nachhaltige Entwicklung Eberswalde, 17-20. https://orgprints. org/27169/.

Munsterhjelm, Camilla, Olli Peltoniemi, Mari Heinonen, Outi Hälli, Marija Karhapää, and Anna Valros. 2009. Experience of moderate bedding affects behavior of growing pigs. Applied Animal Behavior Science 118: 42-53. https://doi.org/10.1016/j.applanim.2009.01.007.

Platto, S., Q. Zhu, A. Guo, Q. He, S. Hu, A. Valros, and A. Irwin. 2020. Chinese farmers' attitude towards the improvement of animal welfare in their facilities. Animal Welfare 29 (1): 99-112.

Precht, Richard. 2016. Animals think. The right of animals and the limits of humans. Munich: Goldmann Verlag.

Rolink, Diethard. 2019. Lack of skilled workers in agriculture. https://www.topagrar.com/management-undpolitik/news/fachkraeftemangel-in-der-landwirtschaft-11566914.html. Accessed 16 December 2019. (In German).

Rozin, Paul. 2005. The meaning of "natural": Process more important than content. Psychological Science 16 (8): $652-658$.

Schneider, Yvonne. 2013. Factors influencing tail biting in fattening pigs under various environmental conditions. Dissertation. https://d-nb.info/1050978161/34. Accessed 16 December 2019. (In German).

Scholz, Brigitte. 2004. The barn door is wide open. Livestock farming in the professional public relations work in Bavaria. In Between feed trough and commercial. Farm animal husbandry in society and the media, ed. Johann Kirchinger, 75-87. Regensburg. (In German). 
Scholz, Tobias 2015. Chamber of agriculture North Rhine - Westphalia. Annual report. Experimental and Training Centre Agriculture "Haus Düsse". Schwein. https:/www.landwirtschaftskammer. de/duesse/wir/jahresbericht/2015/jahresbericht-2015-gesamt.pdf. Accessed 13 December 2019. (In German).

Simons, Johannes, Luy, Jörg, Vierboom, Carl, Härlen, Ingo, Klink-Lehmann, Jeanette and Hartmann Monika. 2018. Acceptance of farm animal husbandry in Germany - results of the psychological and ethical investigation of determinants. In SocialLab - animal husbandry in the reflection of society, ed.Christoph, Schulz, Inken, 151-156. Journal of Consumer Protection and Food Safety. (In German). https:/literatur. thuenen.de/digbib_extern/dn059720.pdf

Sundrum, Albert. 2015. Position paper on animal welfare. Animal welfare is incompatible with the prevailing production diseases. https://www.uni-kas-sel.de/fb11agrar/fileadmin/datas/fb11/Tierern\%C3\%A4hrung_ und_Tiergesundheit/Dokumente/Positionspapier_zum_Thema_Tierwohl.pdf. Accessed 16 September 2019. (In Ger-man).

Tomasevic, Igor, Ivan Bahelka, Marjeta Čandek-Potokar, Jaroslav Č́tek, Ilija Djekić, Ivona Kušec, Dimitar Nakov, Bartosz Sołowiej, Csaba Szabó, Liliana Tudoreanu, Ulrike Weiler, and Maria Font-i-Furnols. 2020. Attitudes and beliefs of Eastern European consumers towards piglet castration and meat from castrated pigs. Meat Science 160: 107965. https://doi.org/10.1016/j.meatsci.2019.107965.

Turner, Simon, Camerlink, Irene, Baxter, Emma, D’Eath, Richard, Desire, Suzanne and Roehe, Rainer. 2018. Breeding for pig welfare: Opportunities and challenges. In Advances in pig welfare, 399-414. Woodhead Publishing. https://doi.org/10.1016/B978-0-08-101012-9.00012-5

Vanhonacker, Filiep, Wim Verbeke, Els Van Poucke, and Frank Tuyttens. 2008. Do citizens and farmers interpret the concept of farm animal welfare differently? Livestock Science 116: 126-138.

Van Vaerenbergh, Yves, and Thomas Troy. 2013. Response styles in survey research: A literature review of antecedents, consequences, and remedies. International Journal of Public Opinion Research 25 (2): $195-217$.

VDF/BVDF - Verband der Fleischwirtschaft e.V. \& Bundesverband der Deutschen Fleischwarenindustrie (Meat industry association \& Federal Association of the German Meat Industry). 2019. Economic development of the German meat sector. https://www.bvdf.de/presse/mgv2019-pressemeldung-gemeinsam. (In German).

Vermeer, Herman, and Hans Hopster. 2018, 2018. Operationalizing principle-based standards for animal welfare - indicators for climate problems in pig houses. Animals 8 (4, 44). https://doi.org/10.3390/ani8040044.

Wagner, Pia, and Linda Hering. 2014. Online-survey. In Handbook methods of empirical social research, ed. N. Baur and J. Blasius, 661-673. Wiesbaden: Springer VS. https://doi.org/10.1007/978-3-531-18939-0_48.

Wehmeier-Graf, Sandra. 2016. Exit from non-curative interventions in pigs. https://verbraucherschutz. sachsenanhalt.de/fileadmin/Bibliothek/Politik_und_Verwaltung/MS/LAV_Verbraucherschutz/ veterinaermedizin/veranstaltungen/fachgespraeche_fb4/fachgespraech2016/2016-12-08_Ausstieg_aus niht_kurativen_Eingriffen_bei_Schweinen.pdf. Accessed 16 September 2019. (In German).

Wellner, Katharina, Theuvsen, Ludwig, Heise, Heinke. 2019. The willingness of German farmers to participate in the animal welfare initiative - what influences it? Conference Paper, German Association of Agricultural Economists (GEWISOLA), 59th Annual Conference, Braunschweig, Germany. doi: https://doi. org/10.22004/ag.econ.292274. (In German).

Wenke, Cindy, Janina Pospiech, Tobias Reutter, Bettina Altmann, Uwe Truyen, and Stephanie Speck. 2018. Impact of different supply air and recirculating air filtration systems on stable climate, animal health, and performance of fattening pigs in a commercial pig farm. PLoS One 13 (3): e0194641.

Wright, Kevin. 2005. Researching internet-based populations: Advantages and disadvantages of online survey research, online questionnaire authoring software packages, and web survey services. Journal of ComputerMediated Communication 10 (3). https://doi.org/10.1111/j.1083-6101.2005.tb00259.x.

Yeo, Uk-Hyeon, In-Bok Lee, Rack-Woo Kim, Sang-Yeon Lee, and Jun-Gyu Kim. 2019. Computational fluid dynamics evaluation of pig house ventilation systems for improving the internal rearing environment. Biosystems Engineering 186: 259-278.

Publisher's Note Springer Nature remains neutral with regard to jurisdictional claims in published maps and institutional affiliations. 